\title{
The Analysis of Social Governance Problem of Floating Population of Urban Ethnic Minorities at Present
}

\author{
Wang Xiaojing \\ School of Public Management (SPM) \\ Yunnan University of Finance and Economics, P. R. China \\ (258016567@qq.com)
}

\begin{abstract}
The problem of floating population of urban ethnic minorities is a comprehensive social governance problem; it is an important issue in the process of urbanization in our country. The government must strengthen the management thinking, adopt various forms to build platform for different nationalities, different cultures communicate with each other, make the ethnic floating population integrate into the management of urban community, and safeguard their legitimate rights and interests, in order to achieve the goals of mutual tolerance harmonious coexistence and common development between various nationalities.
\end{abstract}

Keywords-Urbanization; Social governance; Ethnic minorities; Floating population

\section{INTRODUCTION}

Since the reform and opening, our country has entered an "active period" of the flotation of various nationalities which cross different regions, it result in the growth of urban ethnic minorities floating population, and the development of the city, at the same time also brought challenges to urban ethnic work. In 2014, the conference of central ethnic work pointed out that it cannot take the attitude of "closed-doorism" to the floating population of ethnic minorities, nor a laissez-faire attitude, the key is to manage the two places where the population flow out and inflow [1] .It is a matter of the harmonious development of cities and the overall situation of national unity that must be taken seriously, the city where the population inflow how to use management thinking then to make minority people integrate into the city better.

\section{The Situation of Floating Population OF URBAN ETHNIC MINORITIES}

The so-called floating population of urban ethnic minorities are mainly refers to the population of ethnic minorities who as carriers of national culture, and come from rural and pastoral areas into the city and do not change the household register. The population often referred to who flow in, not including flow out. It included in the scope of urban minorities together with the new comer of ethnic minorities[2]. At present, the proportion of floating population of urban ethnic minorities is on the rise, the residential area has broken the pattern of early reform and opening up which is limited to the local coastal developed cities, gradually flow to the big and middle cities. It appears the characteristics of multiple, wide distribution, and has formed the pattern of "big scattered, small settlement". They are scattered in the Han people and other ethnic groups, and become an important group in the city. According to statistics in 2010, the ethnic floating population in China is close to 30 million [3] , and the vast majority people flow into cities.

As the ethnic minority population flow into the city, the minority population who without local household register is increasing, and gradually become the majority of ethnic minorities in the city. For example, the minority population of Guangzhou is nearly 640000 in 2012 , the minority population who without the household register is about 567000, and the population who has registered is only 63000; the ethnic minority population of Shenzhen is 795000 in March 2011, the population of household registration is only 52000, the others are more than 93\%[4]. From the perspective of flow form, the situation of floating population of urban ethnic minorities is disorder than orderly [5]. This phenomenon had greater pressure to the social security, and become a difficulty to manage the floating population of urban ethnic minorities. To analysis from the education level, the overall culture level of urban ethnic minorities floating population is not high, have a plenty of illiterate or semiliterate, and young adults.For example, according to the sampling survey of Jiangsu province, the proportion of the cultural level under the stage of elementary and middle school of floating population of urban ethnic minorities in Jiangsu province is as high as $46.2 \%[6]$. The analysis from the aspects of employment, the employment of floating population of urban ethnic minorities is relatively single, mainly engaged in ethnic restaurant industry, selling local products and handicrafts and buildings, and processing industries.

The floating population of urban ethnic minorities tends to face high pressure of "adaptive". They not only face the cultural conflict and integration of rural and urban areas, but also face problems with other ethnic conflict and fusion; Not only to break through the obstacles, such as household registration system, to break through the national culture, customs and language obstacle, etc. [7] From the perspective of 
national psychology, the national minority population in the city either in the quantity of population, or in social life is definitely one of the few, is easy to be the "vulnerable groups", and psychological sensitive and fragile. [8] That is a difficult problem in the social governance of urban ethnic minorities floating population.

\section{THE PREDICAMENT OF SOCIAL GOVERNANCE IN THE FLOATING POPULATION OF ETHNIC MINORITIES}

\section{A. The management of urban public is lag}

At present, our country has not established the effective organization and management mechanism for the floating population. The increasing floating population that overloads the operation of urban infrastructure has brought great pressure to the city. At the same time, because the ethnic problems are sensitive and complex, they also bring new difficulties for urban public management. As the cultural level, citizen consciousness, economic income of urban ethnic minorities floating population are relatively low, but their religious consciousness, ego to protect consciousness are relatively strong, it has brought challenges to balance the public management between the "legal" and "moderate".

\section{B. The pressure of social security is increasing}

At present, the problem of disorderly flow and how to get along with the urban community residents, and the security of their selves are more outstanding, such as pressure to the urban social security. Few of them be engaged in theft, drug use, drug trafficking and other disturbing social order, and even gang crime in some places, become a big hidden danger which affecting urban social stability.

\section{The legitimate rights and interests of the urban ethnic minorities floating population is difficult to guarantee}

They are particularly vulnerable in the modern city. In cities, they cannot equally enjoy the same social security and social welfare with urban citizens, the right of labor and employment, skills training, rest, children's education rights and other rights have also been restrictions. At the same time, the urban ethnic work regulations, the management measures of urban ethnic work, urban minority rights which guaranteed by the laws they cannot enjoy equally.

\section{The urban ethnic relations bring new challenges}

Due to the propaganda of ethnic policy is not enough, and the lack of the understanding of ethnic minorities, a few of urban residents has adopted a way of rejection to ethnic minorities under the influence of traditional concepts of residual ethnic discrimination in some cities. For example, they don't respect minority customs and religious beliefs; some local media even appeared the phenomena that violate the national policy, distort and demonizing ethnic image; some industries and units exist ethnic discrimination, such as hotels and taxi which reject to provide service. Due to urban agglomeration and radiation is stronger, some accidental events tend to expand, even distortion caused by mass incidents, produce larger social impact, so as to affect the urban ethnic relations and social stability.

\section{The Analysis of Social Governance ISSUES OF THE FlOATING POPULATION OF URBAN ETHNIC MINORITIES}

\section{A. The contradiction between the social development and mechanism lag}

Due to the influence of urban and rural dual structure and the limitation of the household registration system, social security system of our country and the national work mechanism are still in the "dual-track" run, ethnic floating population from rural and other place can't into the relevant system of the city. This caused a lot of livelihood problems, the basic rights such as social security, welfare of the urban ethnic minorities floating population are difficult to achieve.At the same time, the city's public administration and public services, especially the urban national work departments of national affairs management and public service function is relatively lag, so it can only stay in the later adjustment and management, can't realize the management and service in-depth, and difficult to do warning in advance.

\section{B. The contradiction between the demand of population flow and the lag of urban functions}

The development of market economy, the advancement of urbanization, is bound to drive the unprecedented mobility of the population. But because of the lag of city function, the city unable to carry a large number of floating populations, therefore it can only set the barriers; the management of the floating population is greatly reduced. At the same time, modern city do not have diverse national culture forwardlooking when constructing its function, it is difficult to meet the needs of multi-cultural minority population.

\section{The contradiction of multi-culture collision}

Due to different language, culture, customs, religious beliefs and lack of proper understanding between each other, the friction and disputes appear easily in the exchanges between different nations. On the one hand, a small number of Han residents who lack of knowledge of the ethnic minorities have ethnic discrimination and do not respect for minority customs and religious beliefs. On the other hand, because of the ethnic floating population is lack of understanding of modern urban civilization and the urban lifestyle, they are difficult to adapt, so there will be a continuous process of collision, conflict, and debugging. Because of the ethnic floating population often at a disadvantage situation in the city, they are very sensitive to stimulation and have strong against psychological and rebellious attitude, when the national characteristic and the legitimate rights and interests is ignored, tend to intensify contradictions, thus influence to the stability of the ethnic relations. 


\section{The Path to Perfect the Current City's SOCIAL GOVERnANCE OF THE FLOATING POPULATION OF ETHNIC MINORITIES}

Urban ethnic minorities floating population is a special group, it needs the city government, social organizations, market organizations and citizens to work together, then to solve the problem of social governance, to actively play their respective role and adopt special policies and measures.

\section{A. To expand the diverse functions of city's economy, politics, and culture}

Planning and developing the function of modern city, to constantly enhance the absorption capacity of the floating population is a historic mission that the era has entrusted to for the development of modern city. In light of the characteristics of urban ethnic minorities floating population, broaden the way of urban development of national economy, to explore through promoting the development of national enterprises to drive the ethnic floating population employment, trying to change the present situation of the employment of the floating population of ethnic minorities. To match the economic and political functions of the city, to adapt to the multicultural demand of the modern city, on the one hand, to do well for the development of ethnic cultural industry, on the other hand, should pay attention to urban ethnic and religious multicultural integration. For example, China has 10 national minorities who believe in Islam, in the long historical development, they formed their own unique religious beliefs and customs, therefore, when expanding urban functions, try to meet the special needs of religious culture and living custom of these ethnic minorities, truly implement respect for minority religious culture.

\section{B. Urban ethnic minorities floating population will be incorporated into the urban community management}

In 2014 , the central ethnic work conference pointed out that to solve the problem of urban ethnic minorities floating population rely on community, promote the establishment of mutual embedded in social structures and community environment, pay attention to protect the legitimate rights and interests of ethnic minorities [9].It should take the full advantage of urban community, the scope of the ethnic floating population should be brought into the community management, and gradually establish a national network which consist of 4 level such as city, district, street, neighborhood. The transformation of the past defensive management mode to the service and participative management mode, through community platform of ethnic floating population for education, health, training, project services such as security, improve the legal consciousness, cultivate their sense of identity, promote mental adaptation of ethnic floating population of coordination with the community. In turn, to use the rich resources of the community, safeguard the legitimate rights and interests of the floating population of ethnic minorities. [10]

\section{To strengthen the construction of urban national rule of law}

The fourth plenary session of 18th communist party of China put forward the new demand of promoting the rule of law, it also pointed out the direction of the rule of law in order to strengthen the city's governance. One is to strengthen the formulation of policies and regulations and perfect the work, make the urban ethnic minorities floating population management laws. To speed up the revision of the regulations of the urban ethnic work, to protect the rights and interests of ethnic minorities; to draft and develop the ethnic floating population management ordinance as soon as possible. The second is to enhance the city administration law enforcement. Promote the shift from "heavy power and management" to "heavy rights and service". For example, the city's management could engage community ethnic minority residents or minority flow personnel to participate in city management; to provide the appropriate operation sites for the minority vendors, simplify the registration procedures and other humanized measures, etc. The third is to strengthen the awareness of the rule of law of ethnic floating population. Lead into the city of minority people consciously abide by laws and urban management regulations of the state, make the city better acceptance of ethnic minority people, let the ethnic masses to better integrate into city [11]. At the same time, to guide urban ethnic minorities floating population use legal means to safeguard their legitimate rights and interests.

\section{To mobilize the social intermediary forces participate in the management}

To strengthen the organization construction of urban ethnic minorities floating population, in accordance with the guide to establish a batch of such as ethnic minority communities, religious groups, national research institutions. By raising the ethnic floating population in the degree of organization, make their interests expression into the orbit of cooperatives and systemization of the government, help resolve urban ethnic minorities floating population in the labor and employment, labor remuneration, social communication, to adapt to the actual problems in the aspects of city, in order to make up for the blank of government management. At the same time, to give full play to the city demonstration role in driving the minority elites of all nationalities, guide them to participate in the minority in the management of the floating population. [12]

\section{CONCLUSION}

The historical process of Chinese modernization will inevitably lead to the frontier minority migration and flow. As the city of flow in, to incorporate the ethnic floating population in social governance, through the mutual governance of the government, social organizations, market organizations and the individual, the ethnic floating population should be resolved in the practical problems of the city. To 
emphasize national multi-cultural existence inevitability, adopt various forms to build platform of different nationalities, different cultures communicate with each other; To actively implement the national policy of equality, and gradually make the ethnic floating population in urban community management; To solve the actual problems in the ethnic minorities living, and protect their legitimate rights and interests; To cultivate the ethnic identity and cohesion of the motherland, in order to achieve mutual tolerance between various nationalities, harmonious coexistence and common development purposes.

\section{REFERENCES}

[1] The central ethnic work conference under the state council and the sixth national unity progress commendation congress held in Beijing. People's Daily, The People's Daily, September 30,2014.http://politics.people.com.cn/n/2014/0930/c1024-25763359.html

[2]Tang duoxian. The analysis of the floating population of urban ethnic minorities,[J]. Journal of South-central University for Nationalities (humanities and social science edition), 2009 (2).

[3] Li Jun-qing. The research on the public service of ethnic floating population in the eastern city. [J]. Journal of Chinese administrative management, 2012 (11).

[4] Zheng Xinzhe. The adaptation and integration of urban ethnic floating population. [J]. Journal of South-central University for Nationalities (humanities and social science edition), 2014 (1).

[5] LI Linfeng. The problem of urban ethnic minorities floating population under the vision of social work. [J]. Journal of Heilongjiang National Periodicals, 2006 (1).

[6] State Ethnic Affairs Commission. The Reference Material of National work (inside information). 2009 (4).

[7] HuaYanlong. The thinking of urban minority population flow problem [J]. Journal of Zhongzhou United Front, 2003 (10).

[8] LI Linfeng. The problem of urban ethnic minorities floating population under the vision of social work. [J]. Journal of Heilongjiang National Periodicals, 2006 (1).

[9] The central ethnic work conference under the state council and the sixth national unity progress commendation congress held in Beijing. People's Daily, The People's Daily, September , 30,2014.http://politics.people.com.cn/n/2014/0930/c1024-25763359.html

[10]Lin Yunchang. The "equal protection" of urban ethnic minorities floating population [J]. Journal of the Second Northwest Institute of National (philosophy and social sciences), 2007 (3).

[11] The central ethnic work conference under the state council and the sixth national unity progress commendation congress held in Beijing. People's Daily, The People's Daily, September 30,2014.http://politics.people.com.cn/n/2014/0930/c1024-25763359.html

[12] Wang Xia. Ethnic roblems and Harmonious Society--The Management of Urban Ethnic Minorities Floating Population. [J]. Journal of Brokers, $2006(1)$. 